\section{Retinal artery \\ macroaneurysms: \\ clinical and \\ fluorescein \\ angiographic \\ features in 34 \\ patients}

RA Moosavi, KCS Fong and A Chopdar

\section{Introduction}

Retinal arterial macroaneurysms (MAs) are acquired aneurysmal dilatations of the retinal arteries that usually occur in elderly hypertensive people. ${ }^{1}$ They appear with variable degrees of surrounding retinal haemorrhage or exudation. This paper aims to describe the clinical and fundus fluorescein angiogram (FFA) features of patients with MAs attending the East Surrey Hospital, between 1994 and 2004. With regard to the FFA changes associated with MA, there have been few recent studies $^{2-4}$ and none in the last decade, which describe these changes in detail. We discuss up-to-date management guidelines for this condition.

\section{Methods}

All patients who attended the East Surrey Hospital, between 1997 and 2004, in whom a diagnosis of retinal arterial MAs was made, were identified from hospital records. Photographs and FFAs were examined. The notes of these patients were collected and retrospectively reviewed. Baseline data of the patients were taken including visual acuity and associated ocular and medical conditions.

Details of the type of MA were recorded based on FFA features.

\section{Results (see Table 1)}

A total of 38 MAs were identified in the fluorescein angiograms and photographs of 34 patients. In 31 patients, the MAs were single. One patient had two MAs, one in each eye. One patient had two MAs in the same eye. One
Ophthalmology

Department, East Surrey Hospital, Redhill, Surrey, RH1 5RH, UK

Correspondence: RA Moosavi, Glaucoma Research Unit, Moorfields Eye Hospital, 162 City Road, Islington, London, England EC1V 2PD, UK Tel.: + 44207566 2117; Fax: +442082035597. E-mail: rz199@ yahoo.co.uk

Received: 4 June 2005 Accepted: 1 July 2005 Published online: 2 September 2005
Keywords: retinal artery macroaneurysm; fluorescein angiography; microangiopathy 
Table 1 Patient database

\begin{tabular}{|c|c|c|c|c|c|c|c|c|c|c|c|c|c|c|c|}
\hline $\begin{array}{l}\text { Patient } \\
\text { no. }\end{array}$ & & Sex & $\begin{array}{l}\text { No. of } \\
\text { MAs }\end{array}$ & Eye & $\begin{array}{l}\text { STA/ITA/ } \\
\text { SNA/INA }\end{array}$ & $\begin{array}{l}\text { Order of } \\
\text { arterial } \\
\text { tree }\end{array}$ & $\begin{array}{l}\text { Saccular/ } \\
\text { fusiform }\end{array}$ & $\begin{array}{l}\text { Quiescent/ } \\
\text { haemorrhagic/ } \\
\text { exudative }\end{array}$ & First diagnosis & $\begin{array}{l}\text { Treatment } \\
\text { observed laser } \\
\text { surgery }\end{array}$ & $\begin{array}{l}\text { LASER } \\
\text { Argon/yagno. } \\
\text { of Txs }\end{array}$ & $\begin{array}{l}V / A \\
a t P c\end{array}$ & $\begin{array}{l}\text { V/ } \\
\text { AFinal }\end{array}$ & $\begin{array}{l}\text { F/U time } \\
\text { period }\end{array}$ & General HX \\
\hline 1 & 87 & $\mathrm{~F}$ & 1 & $\mathrm{~L}$ & ITA & 3 & Saccular & Exudative & & & & & & & \\
\hline 2 & 68 & M & 1 & $\mathrm{~L}$ & ITA & 3 & Saccular & Quiescent (h) & $\begin{array}{l}\text { Subhyaloid/ } \\
\text { Vitreous Hge? } \\
\text { cause }\end{array}$ & Observed & - & $6 / 5$ & $6 / 5$ & 2 years & HBP \\
\hline 3 & 79 & $\mathrm{~F}$ & 1 & $\mathrm{R}$ & STA & 1 & Fusiform & Quiescent (h) & & & & & & & \\
\hline 4 & 81 & F & 1 & $\mathrm{R}$ & STA & 1 & Saccular & Haemorrhagic & & & & & & & \\
\hline 5 & 71 & $\mathrm{~F}$ & 1 & $\mathrm{~L}$ & ITA & 3 & Indefinable & Quiescent (h) & & & & & & & \\
\hline 6 & 72 & $\mathrm{~F}$ & 1 & $\mathrm{~L}$ & STA & 1 & Fusiform & Haemorrhagic & & & & & & & $\begin{array}{l}\text { HBP/IHD, } \\
\text { Hyperchol. }\end{array}$ \\
\hline 7 & 81 & M & 1 & $\mathrm{~L}$ & STA & 2 & Saccular & Exudative & $\begin{array}{l}\text { Circinate } \\
\text { exudate? cause }\end{array}$ & Laser & Argon & $6 / 9$ & $6 / 9$ & 4 months & $\begin{array}{l}\text { Smokes } \\
15 / \text { day }\end{array}$ \\
\hline \multirow[t]{3}{*}{8} & 76 & $\mathrm{~F}$ & 3 & $\mathrm{R}$ & STA & 2 & Saccular & Haemorrhagic & & & & & & & \\
\hline & & & & $\mathrm{R}$ & STA & 2 & Fusiform & Haemorrhagic & & & & & & & \\
\hline & & & & $\mathrm{R}$ & ITA & 2 & Fusiform & Haemorrhagic & & & & & & & \\
\hline 9 & 73 & $\mathrm{~F}$ & 1 & $\mathrm{R}$ & STA & 2 & Saccular & Haemorrhagic & & & & & & & \\
\hline 10 & 78 & $\mathrm{~F}$ & 1 & $\mathrm{R}$ & STA & 2 & Fusiform & Quiescent (h) & & & & & & & \\
\hline 11 & 86 & $\mathrm{~F}$ & 1 & $\mathrm{R}$ & STA & 1 & Saccular & Quiescent (h) & & & & & & & HBP \\
\hline 12 & 74 & $\mathrm{~F}$ & 1 & $\mathrm{~L}$ & STA & 2 & Saccular & Haemorrhagic & $\begin{array}{l}\text { ARMD-related } \\
\text { subretinal Hge }\end{array}$ & Observed & - & $6 / 60$ & $\mathrm{CF}$ & 3 months & HBP, Angina \\
\hline \multirow[t]{2}{*}{13} & 93 & $\mathrm{~F}$ & 2 & $\mathrm{R}$ & STA & 2 & Saccular & Quiescent (h) & & & & & & & \\
\hline & & & & L & ITA & 3 & Saccular & Quiescent (h) & & & & & & & \\
\hline 14 & 70 & $\mathrm{~F}$ & 1 & $\mathrm{~L}$ & ITA & 2 & Saccular & Exudative & MA & Observed & - & $\mathrm{CF}$ & $6 / 60$ & 3 months & $\begin{array}{l}\text { HBP, Hyperchol. } \\
\text { Rheumatoid } \\
\text { arthritis }\end{array}$ \\
\hline 15 & 36 & $\mathrm{~F}$ & 1 & $\mathrm{R}$ & ITA & 3 & Indefinable & Quiescent (h) & & & & & & & \\
\hline 16 & 67 & F & 1 & $\mathrm{R}$ & INA & 1 & Fusiform & Quiescent (e) & MA & Observed & - & $6 / 9$ & $6 / 12$ & 3 months & HBP/DVT/AF \\
\hline 17 & 71 & $\mathrm{M}$ & 1 & $\mathrm{~L}$ & ITA & 1 & Saccular & Quiescent (h) & $\begin{array}{l}\text { Vitreous Hge? } \\
\text { cause }\end{array}$ & Observed & - & HM & $6 / 6$ & 1 months & HBP/AAA \\
\hline 18 & 92 & F & 1 & $\mathrm{R}$ & ITA & 3 & Fusiform & Quiescent (h) & & & & & & & \\
\hline \multirow[t]{2}{*}{19} & 77 & $\mathrm{M}$ & 2 & $\mathrm{R}$ & ITA & 1 & Saccular & Exudative & & & & & & & \\
\hline & 75 & $\mathrm{~F}$ & 1 & $\mathrm{R}$ & $\begin{array}{l}\text { ITA } \\
\text { ITA }\end{array}$ & $\begin{array}{l}1 \\
2\end{array}$ & $\begin{array}{l}\text { Saccular } \\
\text { Saccular }\end{array}$ & $\begin{array}{l}\text { Exudative } \\
\text { Haemorrhagic }\end{array}$ & & & & & & & \\
\hline 21 & 78 & $\mathrm{~F}$ & 1 & $\mathrm{R}$ & SNA & 1 & Indefinable & Exudative & $\begin{array}{l}\text { Preretinal + } \\
\text { vitreous Hge? } \\
\text { SRNVM }\end{array}$ & Observed & - & $6 / 6$ & $6 / 9$ & 2 weeks & - \\
\hline 22 & 78 & $\mathrm{~F}$ & 1 & $\mathrm{R}$ & STA & 3 & Indefinable & Quiescent (h) & MA & Observed & & $6 / 12$ & $6 / 12$ & 0 & HBP \\
\hline 23 & 85 & $\mathrm{~F}$ & 1 & $\mathrm{R}$ & ITA & 2 & Indefinable & Haemorrhagic & $\mathrm{RD}$ & Vitrectomy & & $\mathrm{CF}$ & $6 / 60$ & 3 months & $\begin{array}{l}\text { BE, AMD, } \\
\text { LE, BRVO }\end{array}$ \\
\hline 24 & 52 & M & 1 & $\mathrm{R}$ & STA & 1 & Fusiform & Haemorrhagic & $\begin{array}{l}\text { PVD } \\
\text { Haemorrhagic }\end{array}$ & Observed & - & $6 / 6$ & & & - \\
\hline 25 & 81 & $\mathrm{~F}$ & 1 & $\mathrm{R}$ & STA & 2 & Saccular & Haemorrhagic & MA & Observed & - & $6 / 18$ & $6 / 24$ & 6 months & $\begin{array}{l}\text { HBP/IHD, } \\
\text { Hyperchol. }\end{array}$ \\
\hline
\end{tabular}




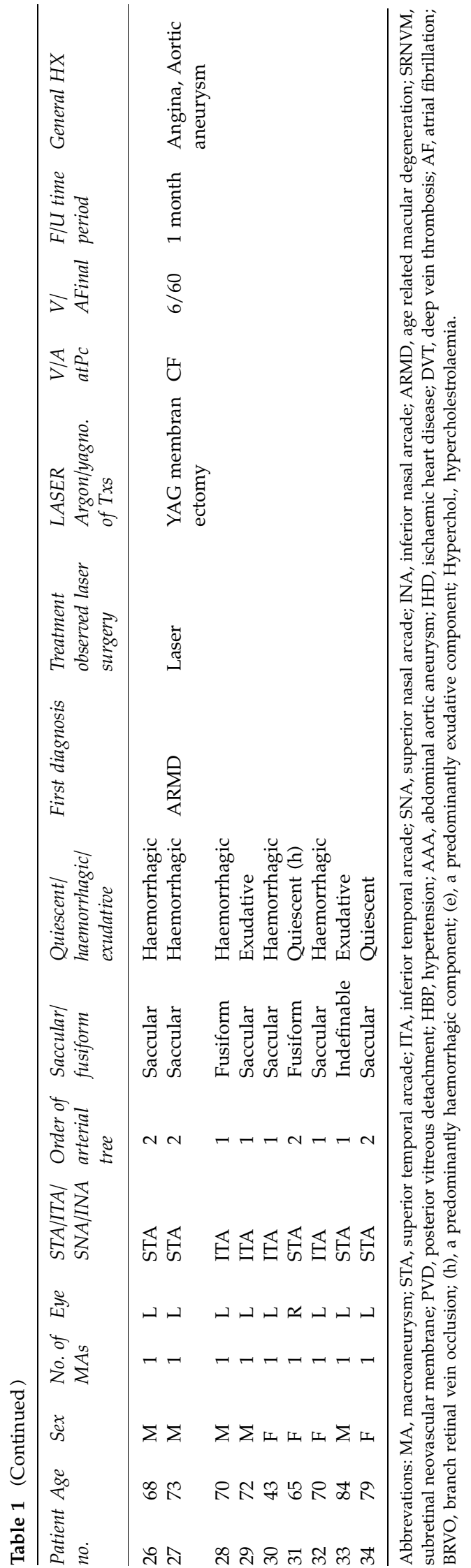

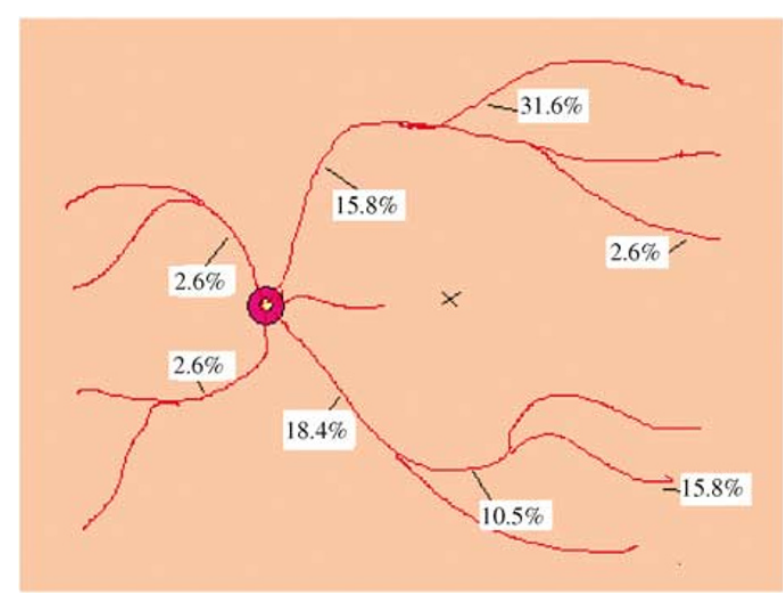

Figure 1 Distribution of MAs in 34 patients.

patient had three MAs all in the same eye. Full medical records were obtained in 14/34 patients. The age at presentation ranged from 36 to 93 years, with a mean of 73.7 years. A female preponderance was noted with $24 / 34(70 \%)$ female patients, and 10/34 (30\%) male patients. Of the 14 cases, where partial or full records were available there was a history of previous MA in $1 / 14$, branch retinal vein occlusion (in the contralateral eye) in $1 / 14$, and age related macular degeneration (AMD) in $1 / 14$. There was a history of hypertension in 9/14 (64.3\%), ischaemic heart disease in 4/14,

hypercholestrolaemia in $4 / 14$, aortic aneurysm in $2 / 14$, and rheumatoid arthritis in 1/14 (35.3\%).

MAs were found in the left eye in 17 cases, and in the right eye in 21 cases. The MAs were seen most commonly (94.7\%) in the temporal half of the retina, with an almost equal distribution between the superotemporal (50\%) and inferotemporal arcades (44.7\%) (see Figure 1).

\section{Definitions}

Since the extent of blood-retinal barrier disruption determines the nature of visual impairment, we classified the MAs in terms of their barrier function similar to a protocol first used by Lavin $e t \mathrm{al}^{1}$ in their study of 40 patients with MA.

Haemorrhagic MAs were defined as MAs where haemorrhage is the major component, extending more than one disc diameter, and responsible for loss of visual acuity (Figure 2). Exudative MAs were defined as MAs in which the exudate is the major component, measuring more than one disc diameter and responsible for loss of visual acuity (Figure 3). Quiescent MAs were defined as MAs in which there is no haemorrhage or exudate, or MAs in which haemorrhage and/or exudate exists, but it spares the macula, and there is no loss of visual acuity. 
They were further subdivided into those MAs with a predominantly haemorrhagic component, and those with a predominantly exudative component.

Each macroaneurysm was classified according to its anatomical nature: 'saccular' or 'fusiform'. These terms have also been described as 'blow-out' and 'cuffed', respectively. ${ }^{5}$ Fusiform MAs are characterized by a circumferential widening of the retinal artery (Figure 4), whereas saccular MAs represent localized outpocketings of the retinal artery wall ${ }^{6}$ (Figure 5). Where the

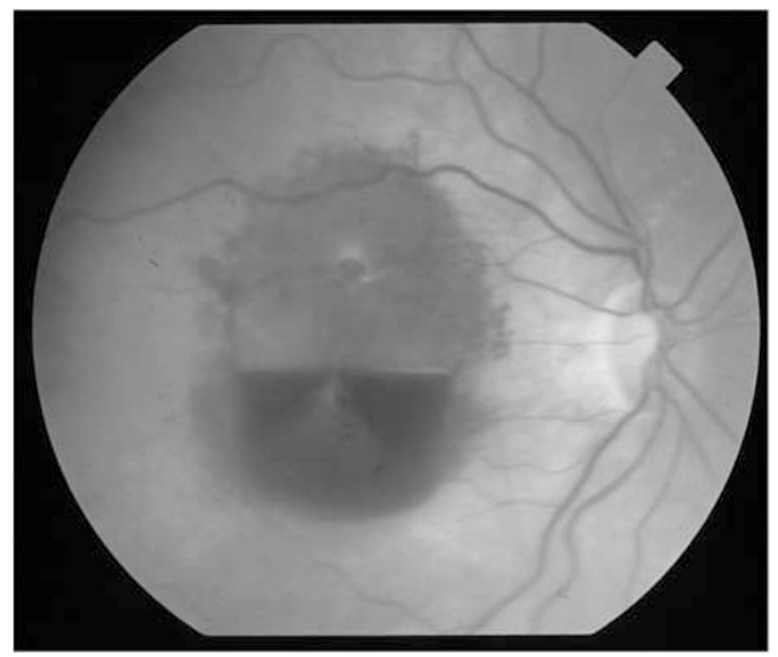

Figure 2 Haemorrhagic MA. This photograph shows haemorrhage at the subretinal, intraretinal, and preretinal levels. anatomical nature of the aneurysm was unclear, the MA was described as 'indefinable'.

Type

Of the 38 MAs, 32 were identifiable as either saccular or fusiform. In total, 22/32 (68.75\%). were saccular, and of these saccular MAs: 10 (45.5\%) were haemorrhagic, six $(27.3 \%)$ were exudative, and six $(27.3 \%)$ were quiescent. All of the six quiescent saccular MAs showed a

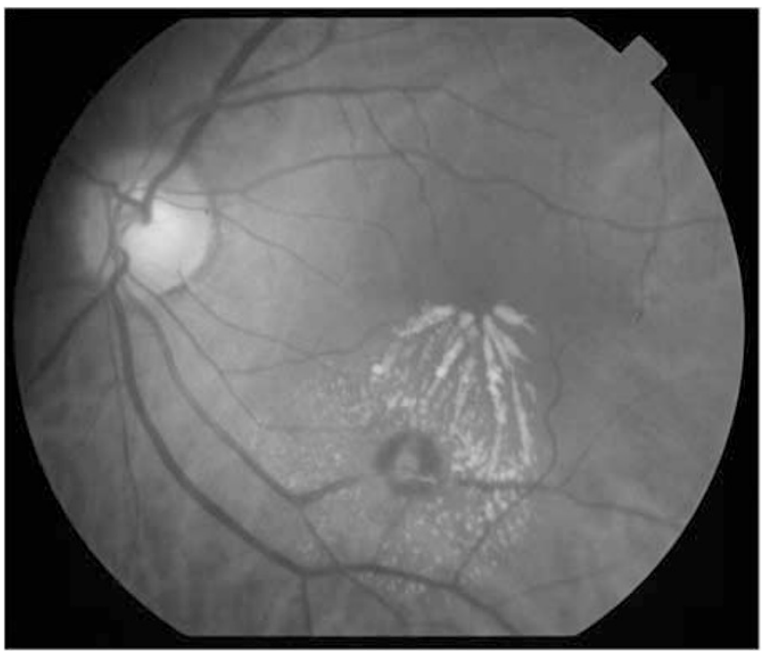

Figure 3 Exudative MA. This photograph shows exudate from an inferotemporal macroaneurysm.

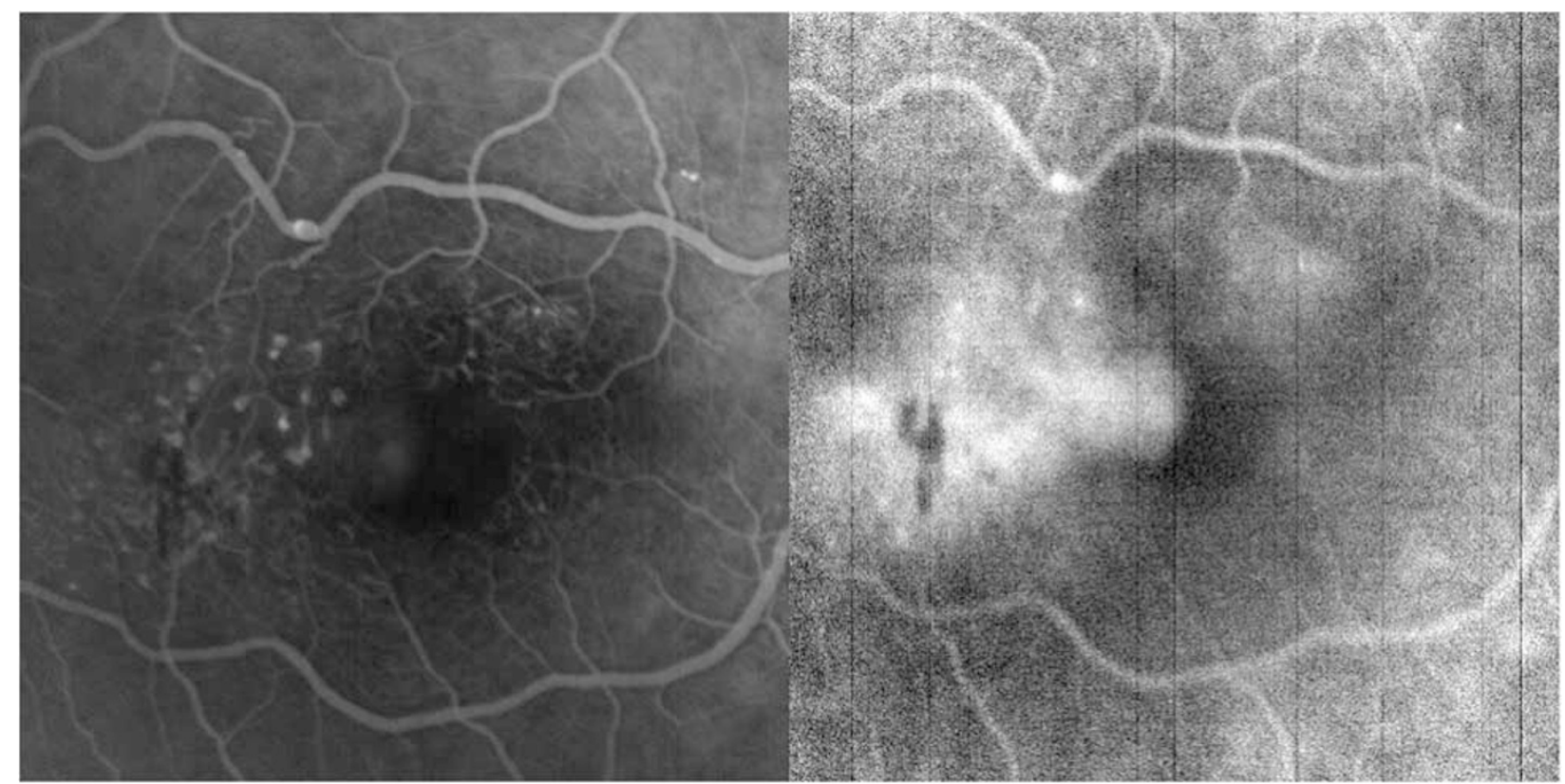

Figure 4 Fusiform MA with microangiopathic changes. This early and late fluorescein angiogram shows a fuisform MA. Adjacent to the fovea is microangiopathy, which leads to chronic exudation and cystoid macular oedema. 


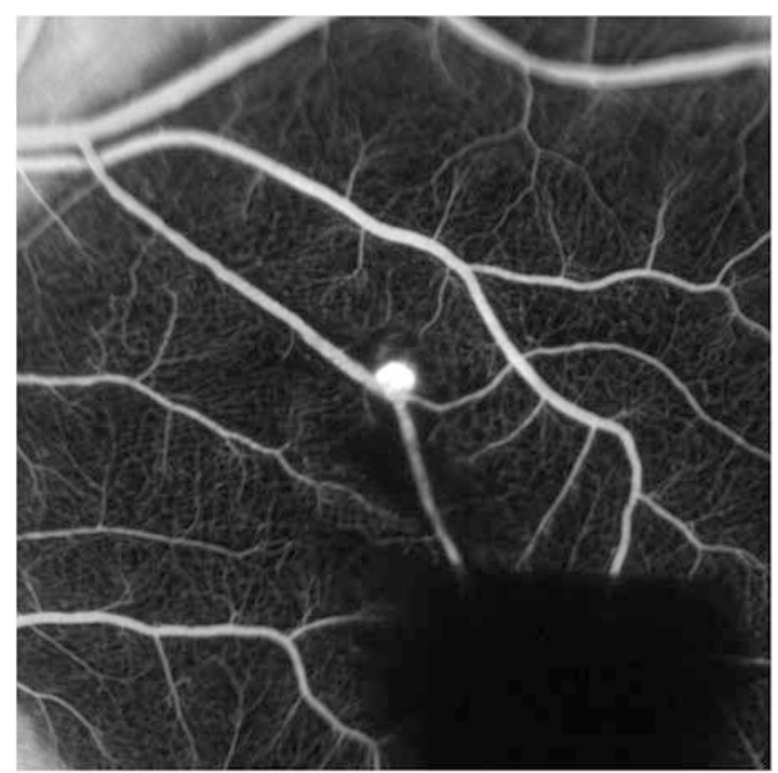

Figure 5 Saccular MA. This fluorescein angiogram shows a saccular MA at the bifurcation of a second-order artery of the superior temporal arcade.

predominantly haemorrhagic nature. In total, $72.7 \%$ of the saccular MAs showed haemorrhage as the predominant feature (Table 2). Of the 10 fusiform MAs: five were haemorrhagic, none were exudative, and five were quiescent. Of the five quiescent fusiform MAs, four showed a predominantly haemorrhagic nature and one showed a predominantly exudative nature. So, in total $90 \%$ of fusiform MAs showed haemorrhage as the predominant feature (Table 2).

\section{Distribution}

Figure 1 shows the distribution of the all types of MA along the arterial tree. Table 3 shows that both saccular and haemorrhagic MAs occurred predominantly on the second order of the arterial tree, whereas fusiform and exudative MAs occurred predominantly on the first order of the arterial tree.

\section{Initial diagnosis}

MA was recorded as the cause of the clinical appearance in four of the 14 cases in which records are available. Of the rest, intraocular haemorrhage/exudate of unknown cause (three cases), AMD/SRNVM-related haemorrhage (three cases), posterior vitreous detachment (one case), and vitreous haemorrhage due to retinal detachment (one case) were listed as the initial diagnosis.
Table 2 A comparison of the proportion of haemorrhagic and exudative saccular and fusiform macroaneurysms

\begin{tabular}{lrr}
\hline & Saccular & Fusiform \\
\hline Haemorrhagic & $16(72.7 \%)$ & $9(90 \%)$ \\
Exudative & $6(27.3 \%)$ & $1(10 \%)$ \\
\hline
\end{tabular}

Table 3 Analyses of the site on the arterial tree of haemorrhagic and exudative, saccular, and fusiform macroaneurysms

\begin{tabular}{lrccc}
\hline & Haemorrhagic & Exudative & Saccular & Fusiform \\
\hline Order 1 & $9(31.1 \%)$ & $6(66.7 \%)$ & $8(36.4 \%)$ & $5(50 \%)$ \\
Order 2 & $14(48.3 \%)$ & $2(22.2 \%)$ & $11(50 \%)$ & $4(40 \%)$ \\
Order 3 & $6(20.7 \%)$ & $1(11.1 \%)$ & $3(13.6 \%)$ & $1(10 \%)$ \\
\hline
\end{tabular}

\section{Treatment}

Active treatment was administered in three cases, one YAG membranectomy for a saccular haemorrhagic MA (Figure 6), and perianeurysmal focal argon lasers for saccular exudative MAs. One other case was treated with vitrectomy for presumed retinal detachment. The rest were observed without treatment.

\section{Discussion}

Clinically and histologically, MAs are characterized by a dynamic process of formation, enlargement (with or without blood-retinal barrier disruption), and, for the majority, gradual thrombosis, fibrosis, and spontaneous involution after a variable time period.

Isolated MAs are almost always seen in the elderly, ${ }^{1}$ our study showing an average age of 73.7 years, in agreement with another study showing an average of 69.7 years. ${ }^{7}$ Several studies have reported that women represent the large majority of patients with MAs, ${ }^{7}$ this is not necessarily only due to the excess of female patients in the older population. Intracranial saccular aneurysms are structurally similar, and those, particularly on the internal carotid artery, are also more common among women ${ }^{7}$ over the age of 40 years. ${ }^{1}$ This female preponderance has been attributed to both heritable and hormonal causes, ${ }^{7}$ and it is likely that similar pathogenic factors operate in these two types of aneurysm.

Hypertension is a prominent feature in patients with MAs, ${ }^{1}$ noted in approximately $75 \%$ (64.3\% in our study), and thought to be a significant risk factor for retinal arterial MAs. Histopathologically, ageing of arterioles is caused by an increase in intimal collagen and a replacement of medial smooth muscle fibres with collagen. The arterial wall becomes less elastic and more susceptible to dilatation from elevated hydrostatic 


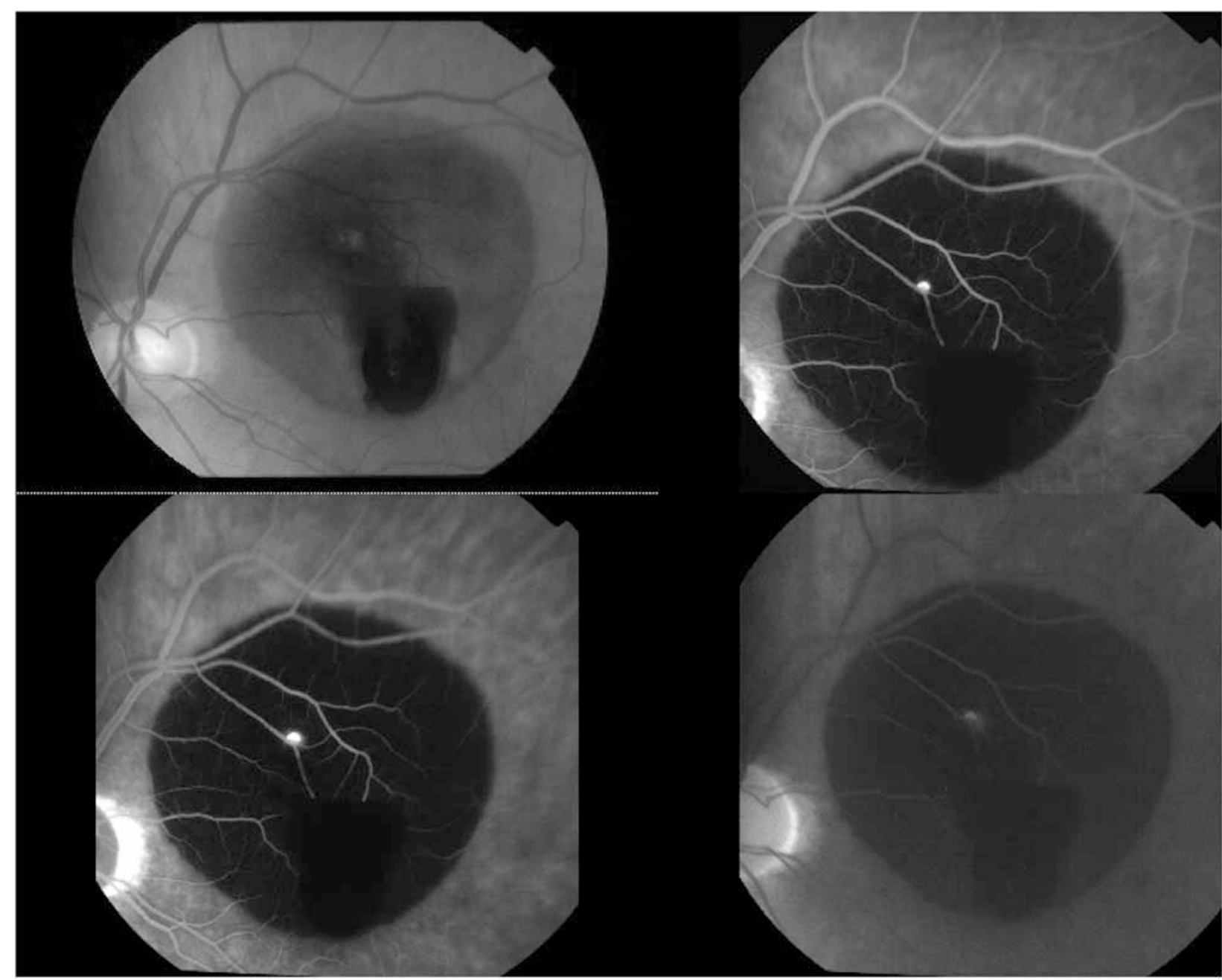

Figure 6 Haemorrhagic MA. Photograph and fluorescein angiogram showing MA with haemorrhage at the subretinal and prehyaloid levels. The patient received a YAG membranectomy, to allow the blood to drain inferiorly. Unfortunately the visual acuity did not improve beyond 6/60 because of intraretinal and subretinal haemorrhage.

pressure. Hypertensive patients also have raised hydrostatic pressures. The Laplace equation states that a raised transmural pressure is directly proportional to a raised wall tension, which might predispose to MA formation. ${ }^{7}$ These changes are similar to those seen in the sclerotic phase of hypertensive retinopathy. ${ }^{1}$

Hypertension can lead to hyaline degeneration of vessel walls, loss of autoregulatory tone, and arterial dilatation. ${ }^{7}$ Systemic hypertension and haemodynamic stress have been implicated in the pathogenesis of intracranial aneurysms, ${ }^{7}$ studies of cerebral aneurysms showing that up to $50 \%$ ruptured during events associated with transient arterial hypertension, emphasizing the importance of mechanical events, ${ }^{1}$ and suggesting that such events may have a role in the rupture of retinal artery MAs. Lavin et $a l^{1}$ showed that patients with haemorrhagic MAs had higher systolic blood pressures and significantly fewer associated retinal vein occlusions than other types of MA. A higher systolic blood pressure seen in patients with haemorrhagic MAs may have contributed to the haemorrhage both by the increased transmural tension and by a greater amplitude of pulsations, causing mechanical vascular damage. In our study $7 / 9$ of patients with a history of hypertension had haemorrhagic changes.

MAs are frequently associated with other ocular conditions including retinal vascular occlusions and retinal emboli. ${ }^{1}$ RVOs are frequently seen in association with MAs, and are also described in other arterial diseases such as Coats' disease and Lebers miliary aneurysms, uncommonly in association with haemorrhagic MAs, but commonly seen in association with nonhaemorrhagic MAs. ${ }^{1}$ Venous occlusion may be statistically associated with MA in the following 
ways - (a) both diseases may have similar risk factors, such as age and hypertension, (b) venous occlusion may be caused by an adjacent MA or (c) a MA may result from venous occlusion. Where a venous occlusion causes MA, chronic venous stasis has led to local arterial thrombosis, endothelial damage, and aneurysm formation. Alternatively, a MA may arise at the origin of a dilated collateral vessel because of local arterial wall weakness or local turbulent flow. ${ }^{7}$

In most cases, MAs arise on the first three orders of the arterial tree, though occasionally they arise on small branches of the major arterial tree..$^{5}$ The latter tend to reach a very large size and promote severe exudative phenomena in the retina. Fusiform MAs are thought to be more prone to exudation, though our study, have shown that haemorrhage predominates. Previous studies have shown that saccular MAs in general are more prone to bleed, especially those on the first three orders of the arterial tree, but a large blow out on smaller arterioles may be exudative. This may be due to the fact that where the perfusion pressure is high as in the first three orders of the arterial tree, the thin stretched arterial sac is relatively easily perforated, whereas the perfusion pressure is lower in the smaller arterioles predisposing more to exudation. ${ }^{5}$ Our study suggests that whereas, there is a preponderance of haemorrhagic over exudative changes in the first three orders of the arterial tree, those exudative changes that do occur, do so with decreasing frequency the further away from the optic disc the MA occurs. Arteries close to the disc have larger diameters and increased flow rates compared to peripheral vessels. These factors will increase transmural stress in these arteries, and may contribute to haemorrhage. ${ }^{1}$

MAs frequently occur at arteriovenous crossings. At the point where arterial and venous walls are in contact the adventitial layer is absent, and the two vessels share a common coat. The arterial wall has less structural support at this point and may be prone to aneurysm formation. ${ }^{1}$

One of the features of our study was that FFAs were performed on all our patients. Findings show that, although sizes were variable, MAs appeared to be fusiform or saccular. Fusiform MAs show rapid filling in the early arterial phase and involve most of the arterial circumference. Saccular MAs show minimal early filling, with good filling in the middle or late phases of the angiogram. The rate of filling appears to be decided by the size of the aneurysm neck. Fluorescence of MAs is not necessarily homogenous and many show irregular inhomogeneous filling, thought to represent intraluminal clot formation, or endothelial cell proliferation. Occasionally the MA is masked by overlying blood. ${ }^{1}$ Subsequent changes may include arteriolar constriction proximal to the MA, arteriolar sheathing distal to the
MA, and pigment clumps resulting from intratretinal haemorrhage and disruption of the RPE. ${ }^{5}$ The 'Z-shaped' kinked (Figure 7) appearance at the site of the resolved MA may result from fibrotic changes in the media of the arterial wall causing traction on the adventitial portion in that segment, leading to shortening of the artery.

Counterforces between the fibrous contracture and the tensile strength of the adventitial attachments to the internal limiting membrane of the retina will lead to the appearance of the Z-shaped kink. ${ }^{5}$ Other angiographic findings include widening of the capillary free zone and intra-arterial collateral vessels. Areas of microangiopathy are often associated with fluorescein leakage in the area around the $\mathrm{MA}^{2}$ (Figure 4).

FFA may be of limited utility because of blocked fluorescence secondary to haemorrhage. Some studies describes the usefulness of indocyanine green angiography in the diagnosis of MA, where the associated haemorrhage hides the aneurysm. ${ }^{8,9}$ Since the absorption and emission spectra of indocyanine green are in the near-infrared range, the dye can be clearly seen through the haemorrhage, revealing structures that would otherwise be obscured. This is shown to be the case when in five eyes, where haemorrhage prevents clinical and FFA visualization of the aneurysm. ${ }^{9}$

Haemorrhage occuring with acute aneurysmal decompensation, may present at a number of levels

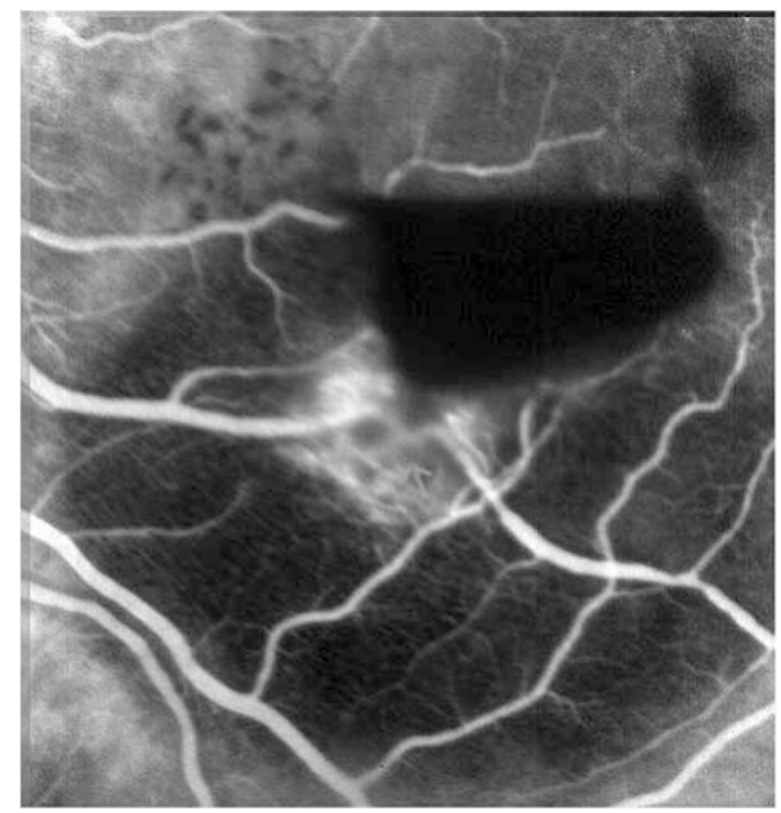

Figure 7 ' $Z$ '-shaped kink. This fluorescein angiogram shows the fibrotic changes in the media of the arterial wall causing traction on the adventitial portion in that segment, leading to shortening of the artery. Counterforces between the fibrous contracture and the tensile strength of the adventitial attachments to the internal limiting membrane of the retina lead to the appearance of the ' $\mathrm{Z}$ '-shaped kink. 
-intra- and subretinal, preretinal, subhyaloid, and intravitreal (Figure 2). Large aneurysmal dehiscences produce haemorrhage at all levels. ${ }^{5}$ Where the haemorrhage is primarily preretinal, it is likely arterial rupture has occurred on the vitreal side of the MA. Posterior or posterolateral rupture of the aneurysm probably leads to intra- and subretinal haemorrhage. Preretinal and intraretinal haemorrhages usually reabsorb without complication, however in cases in with dense subretinal haemorrhage, severe damage to the retina can occur, especially when the haemorrhage is thick and associated with age-related macular degeneration. This is because subretinal blood is toxic and causes severe and irreversible damage to the retina. This outer retinal toxicity is presumably caused by three factors: a mechanical barrier effect that prevents metabolic exchange between the retinal pigment epithelium and outer retina: iron-related toxicity: and fibrin-mediated retinal damage. ${ }^{9}$ Haemorrhages in the submacular space may produce secondary morphologic changes within the macula, causing permanent architectural damage to the retinal pigment epithelium and photoreceptors, and usually result in central visual loss. ${ }^{2}$

Exudation tends to occur with chronic aneurysmal decompensation, and prolonged abnormal leakage of plasma contents across the aneurysmal wall. Exudative MAs may present as perianeurysmal exudates only, (these do not affect the vision and have the best prognosis), and/or macular exudates. In cases with abundant circumaeurysmal exudates a high rate of transmural leakage seems likely. Scanty perianeurysmal leakage suggests a low leakage rate. ${ }^{5}$

Chronic exudation may be due to direct aneurysmal leakage or leakage from small incompetent vessels surrounding the MA. ${ }^{2}$ This 'microangiopathy' refers to areas of secondary microvascular angiopathic change adjacent to the MA, rather than the MA itself. This is typified by intraretinal microvascular abnormalities including capillary microaneurysms, dilatation, tortuosity, leakage, nonperfusion, and dropout (Figure 4). Robertson $^{3}$ attributed the vascular changes to chronic venous obstruction from underlying hypertensive and arteriosclerotic disease, because one of his patients manifested the changes before developing the MA. It remains unclear whether abnormal capillary permeability is a precursor to the development of MAs, or a secondary response to local leakage from MA. Lewis et $a l^{4}$ speculated that the changes may represent a compensatory response for poor local blood flow and hypoxia from either embolic phenomena or mechanical forces resulting from arterial wall expansion. ${ }^{2}$

Visual loss is influenced not only by the proximity of the MA to the macula, but also by the presence of oedema, exudates or haemorrhage, and its severity duration, and position. ${ }^{1}$ It may persist due to preretinal fibrosis, pigment epithelial change, or ongoing macular arterial occlusion.

MAs have variable clinical presentations, are frequently misdiagnosed before fluorescein angiography and are regarded as a masquerade syndrome. ${ }^{10}$ Haemorrhagic MAs are the most frequently misdiagnosed. For instance, submacular haemorrhage is commonly associated with AMD, presumed ocular histoplasmosis, high myopia, and trauma. ${ }^{11}$ MAs have also been mistaken for choroidal melanomas. ${ }^{12}$ Other conditions associated with subretinal haemorrhage include angioid streaks, tumours, other causes of $\mathrm{CNV}$, diabetic retinopathy, CRVO, and coagulopathies. ${ }^{11}$ Subretinal haemorrhage in MAs is typically extensive, dense, overlies an artery, is not centred on the macula, and has vitreous extension. Careful fundus examination supplemented by FFA, which may have to be repeated several times, usually establishes the diagnosis. ${ }^{1}$ Rapid and correct diagnosis is very important in subretinal haemorrhage due to MA compared with AMD cases, due to retinal toxicity. ${ }^{9}$ New surgical techniques involving pars plana vitrectomy and tissue plasminogen activator have been developed to remove the haemorrhage. ${ }^{9}$ The efficacy of these new treatments is still being evaluated. One study found nine eyes with submacular haemorrhages caused by retinal arterial MA whose best corrected VA improved after submacular surgery with tissue plasminogen activator-assisted thrombolysis. ${ }^{9}$

'Slow to clear' vitreous haemorrhage may hide a ruptured aneurysm. In these cases clinicians are advised to have a high index of suspicion of a MA. A good clinical history should be taken in a patient with a vitreous haemorrhage to try to establish the likely cause: in older patients, receiving treatment for hypertension, who have arteriosclerosis, who have a nonmyopic correction, who have no recent history of trauma, no diabetic retinopathy, no history of laser treatment or retinal break, an MA or CNV should be suspected as the cause, and more time can be given to wait for the haemorrhage to clear before performing a vitrectomy, than when the cause is thought to be a retinal tear or diabetic retinopathy.

When the haemorrhage clears or is removed, the only sign of a previously ruptured MA may be a vessel kink overlying a 'saddle-shaped' pseudodisciform lesion, which may make diagnosis very difficult if the prior retinal haemorrhage was unrecognized (Figure 8). If this plaque involves the macula, central vision is invariably lost. It is likely that many MAs rupture and close sponteaneously and go unrecognized as the causative lesion in an episode of intraocular haemorrhage. ${ }^{5}$ 


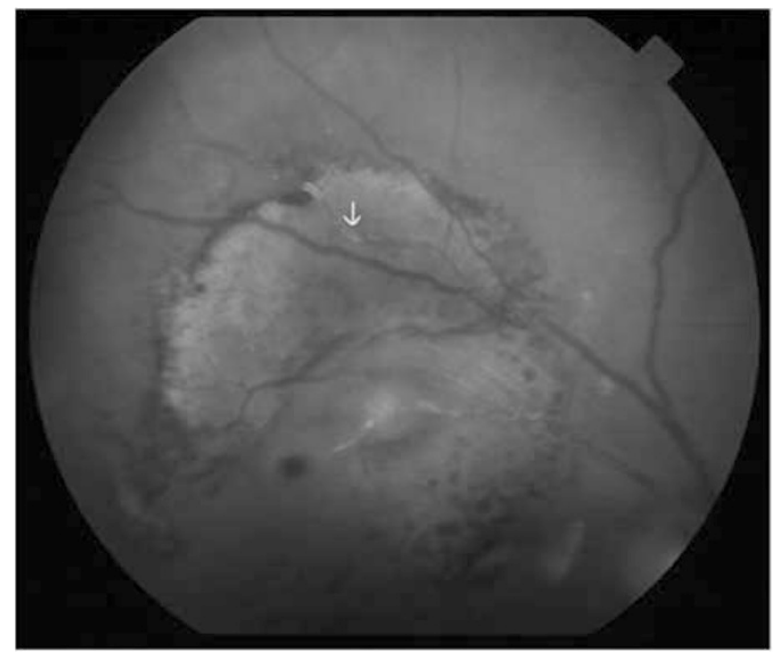

Figure 8 'Z'-shaped kink + pseudodisciform lesion. This photograph shows a vessel 'kink' (shown by arrow), overlying a saddle-shaped pseudodisciform lesion of the retina, in an eye with a previously ruptured MA.

An exudative retinopathy consisting of intraretinal yellow or white lipid deposits is a common finding. Frequently, these deposits adopt a circinate pattern surrounding the MA, but may also appear as a dense accumulation of lipid exudate in the macular region, irrespective to the location of the MA. ${ }^{2}$ The occurrence of exudates at the macula area away from the offending vessel is not unique to retinal MA, as it occurs in other retinal vascular anomalies such as Coats disease, Leber's miliary aneurysms, and von Hippel-Lindau diseases. ${ }^{5}$ MAs with exudation may be misdiagnosed as branch vein occlusion (BVO), or diabetic retinopathy (DR), or AMD especially if these are coexisting conditions. It is most important to differentiate these entities because of the very different treatments available. ${ }^{1}$

The diagnosis of MA should be considered in all patients with intraocular haemorrhage, retinal oedema, or exudates, particularly if atypical features are present.

\section{Treatment}

Although several studies have been published on MAs, there is no clear guidance on their treatment. Our proposed management guidelines are:

1. Unruptured MAs should be observed.

2. A Z-shaped kink indicates a ruptured, resolved and stable MA and does not require treatment.

3. Vitreous haemorrhage thought to have occurred as a result of MA (see above) should be observed for 3-4 months, and removed by vitrectomy if it does not resolve.
4. Subhyaloid or preretinal haemorrhage responds to YAG laser membranectomy. The blood should drain inferiorly and remain behind the posterior hyaloid face of the vitreous. Here there is no need for vitrectomy (Figure 6).

5. Subretinal or intraretinal macular haemorrhage should be left alone as it is not remediable by laser treatment. It usually results in severe visual loss. New interventions include submacular surgery combined with vitrectomy, tissue plasminogen activator assisted thrombolysis, and pneumatic displacement of submacular haematoma. The efficacy of these new treatments are currently being evaluated.

6. Exudative MAs, however, when associated with microangiopathy (Figure 4), are eminently treatable, particularly if seen early. Unless this microangiopathy occurs within $250 \mu \mathrm{m}$ of the perifoveal arcade, the exudative, and microvascular changes can be checked and reversed when treated with fundal argon laser directed at the affected retinal capillary beds. The argon laser is most effective when a grade II laser burn is achieved, according to the Wallow protocol. These usually have a white centre surrounded by a single ring of greyish white peripheral lesion seen clinically during the acute stage. This results in occlusion of choriocapillaris, necrosis of endothelial cells with inflammatory response. The Bruch's membrane remains unaffected. The pigment epithelial cells undergo destructive changes, as do the photoreceptors. During the healed stage they appear as a central brown ring surrounded by a yellowishwhite hypopigmented periphery. ${ }^{13}$

Neither haemorrhagic nor exudative MAs warrant laser treatment directly to the MA itself. Studies have shown that such treatment does not improve the visual outcome. ${ }^{14}$ If the MA has not ruptured, it may do so as a result of the laser treatment, and the patient will be left with a dense visual field defect. If the MA has already ruptured, there is no need to treat with argon laser, as the haemorrhage will clot and resolve on its own; occasionally there may be some recovery of visual acuity, where there is recanalisation of the area by the establishment of a collateral circulation to the vascular obstruction. In this way, blood eventually flows to the distal part of the retinal artery.

\section{Prognosis}

Quiescent MAs invariably have the best visual outcome. The visual prognosis for eyes with symptomatic MA depends on the macular pathology. Eyes with vitreous haemorrhage or premacular haemorrhage recover good vision when the haemorrhage clears, while the vision in those with submacular haemorrhage with or without 
premacular haemorrhage generally remains poor for the reasons mentioned above. ${ }^{8,9}$ In general, however, compared with exudation, patients with haemorrhagic MAs have a better visual prognosis ${ }^{5}$

The limitations of this study are that it is a retrospective study looking at cases of MA over 8 years, and as such we were unable to recover the medical notes in many of the early cases. Insufficient data meant we were unable to assess properly the incidence of predisposing or coexisting systemic and ocular pathology. The population of quiescent MAs are likely to be under-represented, unless identified as an incidental finding; the nature of some types of MA meant that some of their features were indefinable or hidden from view.

However, this study adds further data to the literature that exists on the natural history of a relatively rare condition. Over 8 years we were able to create a relatively large cohort of 34 patients. We provide new information on the importance of some of the more subtle angiographic features of MAs, which has not been reported in any previous study, and which explains and contributes to a modified treatment algorithm for the various manifestations of this condition.

\section{Acknowledgements}

We thank Mr Maxwell Brown, Senior Ophthalmic Medical Photographer at East Surrey Hospital, for his help in producing the images in this article.

\section{References}

1 Lavin MJ, Marsh RJ, Peart S, Rehman A. Retinal arterial macroaneurysms: a retrospective study of 40 patients. $\mathrm{Br} \mathrm{J}$ Ophthalmol 1987; 71(11): 817-825.
2 Rabb MF, Gagliano DA, Teske MP. Retinal arterial macroaneurysms. Surv Ophthalmol 1988; 33(2): 73-96.

3 Robertson D. Macroaneurysms of the retinal arteries. Trans Am Acad Ophthalmol Otolaryngol 1973; 77: OP55-OP67.

4 Lewis RA, Norton EWD, Gass JDM. Acquired arterial macroaneurysms of the retina. Br J Ophthalmol 1976; 60: 21-30.

5 Abdel-Khalek MN, Richardson J. Retinal macroaneurysm: natural history and guidelines for treatment. Br J Ophthalmol 1986; 70(1): 2-11.

6 The Merck Manual of Diagnosis and Therapy: Seventeenth Edition, Section 16-Cardiovascular disorders; Chapter 211-Diseases of the Aorta and its Branches.

7 Panton RW, Goldberg MF, Farber MD. Retinal arterial macroaneurysms: risk factors and natural history. $\mathrm{Br} J$ Ophthalmol 1990; 74(10): 595-600.

8 Humayun M, Lewis H, Flynn Jr HW, Sternberg Jr P, Blumenkranz MS. Management of submacular hemorrhage associated with retinal arterial macroaneurysms. Am J Ophthalmol 1998; 126(3): 358-361.

9 Townsend-Pico WA, Meyers SM, Lewis H. Indocyanine green angiography in the diagnosis of retinal arterial macroaneurysms associated with submacular and preretinal hemorrhages: a case series. Am J Ophthalmol 2000; 129(1): 33-37.

10 Spalter HF. Retinal macroaneurysms: a new masquerade syndrome. Trans Am Ophthalmol Soc 1982; 80: 113-130.

11 Hochman MA, Seery CM, Zarbin MA. Pathophysiology and management of subretinal hemorrhage. Surv Ophthalmol 1997; 42(3): 195-213.

12 Shields CL, Shields JA. Subretinal hemorrhage from a retinal arterial macroaneurysm simulating a choroidal melanoma. Ophthalmic Surg Lasers 2001; 32(1): 86-87.

13 Wallow I. Clinicopathologic correlation of retinal photocoagulation in the human eye. In: Weingeist TA, Sneed SR (eds). Laser Surgery in Ophthalmology. Appelton and Lange, pp 15-27.

14 Brown DM, Sobol WM, Folk JC, Weingeist TA. Retinal arteriolar macroaneurysms: long-term visual outcome. $\mathrm{Br} J$ Ophthalmol 1994; 78(7): 534-538. 